\title{
LOS CUENTACUENTOS: UNA EXPERIENCIA INNOVADORA PARA EL FOMENTO DE LA COMPETENCIA EN COMUNICACIÓN LINGÜÍSTICA A TRAVÉS DEL CUENTO EN ALUMNOS DE TERCER CURSO DE EDUCACIÓN PRIMARIA
}

\section{STORYTELLERS: AN INNOVATIVE EXPERIENCE FOR THE PROMOTION \\ OF COMPETENCE IN LINGUISTIC COMMUNICATION THROUGH THE STORY IN THIRD YEAR STUDENTS OF PRIMARY EDUCATION}

\author{
ANTONio PÉrez Hernández \\ UNIVERSIDAD DE MURCIA \\ a.perezhdz@gmail.com
}

\section{RESUMEN}

Nuestra investigación aprovecha el potencial didáctico de los cuentos para fomentar la competencia en comunicación lingüística en el alumnado de tercer curso de Educación Primaria. Los objetivos planteados incluyen diseñar una actividad innovadora en torno al cuento, analizar las diferencias significativas acaecidas entre pretest y postest y evaluar la utilidad y el grado de satisfacción de la actividad, tanto desde la perspectiva del alumnado participante como desde la de los distintos profesionales de la docencia presentes durante su desarrollo.

Se aúnan aspectos cuantitativos y cualitativos, ubicándonos ante un estudio preexperimental en el que se realizan dos mediciones (una previa a la intervención y otra posterior) y con un diseño descriptivo-comparativo.

Mediante los análisis se evidencia una mejora de la competencia en comunicación lingüística que se refleja, entre otros aspectos, en la mejor comprensión de qué es un adjetivo, un sustantivo, un verbo y de las posibilidades educativas de los cuentos. Se concluye afirmando que la experiencia ha gozado de elevado grado de satisfacción y motivación: la mayoría del alumnado desea repetir una actividad similar.

PALABRAS CLAVE

Literatura infantil; Educación Primaria; Innovación educativa; Competencia lingüística; Métodos educativos

\section{ABSTRACT}

Our work approaches the educational potential of tales to promote linguistic competence in communication in students of third year of Primary Education. The objectives include designing an innovative activity around the tale, analyze the 
significant differences occurred between pretest and posttest and evaluate the usefulness and satisfaction of activity, both from the perspective of the students participating as from the various professionals teaching present during development Quantitative and qualitative aspects come together, placing us before a preexperimental study in which two measurements (prior to intervention and posterior) and a descriptive-comparative design are made.

Through analysis improved linguistic competence in communication that is reflected, among other things, a better understanding of what is an adjective, a noun, a verb and educational possibilities of the stories is evident. It concludes that the experience has enjoyed high degree of satisfaction and motivation: the majority of students want to repeat a similar activity.

\section{KEY WORDS}

Children Literature; Primary Education; Educational Innovation; Linguistic Competence; Educational Methods

$$
\text { * * * }
$$

\section{INTRODUCCIÓN}

En esta investigación planteamos el cuento como centro de interés educativo para el fomento de la competencia en comunicación lingüística del alumnado de tercer curso de Educación Primaria.

Consideramos necesario fomentar dicha competencia debido a que posee un gran valor en la construcción de la identidad infantil (Rosal Nadales, 2010), ofrece mecanismos de análisis y herramientas para la correcta expresión de la lengua oral y escrita (Rodríguez Muñoz, 2010) y posibilita participar mediante el lenguaje en las diferentes esferas de la vida social (Pérez Steve, 2009). En efecto, en la competencia en comunicación lingüística intervienen factores variados "desde los lingüísticos a los psicológicos, pasando por factores sociales, históricos, culturales y, por supuesto, literarios" (Cerrillo y Senís, 2005, 29), necesarios para una adecuada maduración personal.

Los motivos que nos han llevado a decantarnos por los cuentos para el fomento de la señalada competencia son variados. Sandoval (2005) resalta su importancia educativa desde un punto de vista evolutivo y afirma que son uno de los motivadores más relevantes en la etapa de adquisición de la lectura y la escritura y, además, uno de los medios más eficaces para crear y estimular 
el placer por los libros. Aparicio Martínez (2004) reivindica lo señalado al afirmar que fomentan la capacidad de escuchar, intensifican el sentido de la observación, constituyen un gran motivador de actividades lingüísticas y favorecen el desarrollo cognitivo de los niños al mismo tiempo que permite la estructuración temporal.

En efecto, y a fin de evidenciar la contribución de los cuentos para con el fomento de la competencia que nos ocupa, analizaremos las aportaciones recogidas por Guerrero Ruiz $(2008,74)$ desde una óptica cuentística:

- La competencia literaria se construye, entre otros factores, con la progresiva acumulación de conocimientos aportados por los textos, que se orientan hacia el intertexto del lector y de su capacidad para relacionar.

- La formación de la competencia literaria está vinculada muy estrechamente con la lectura, pues leer es la actividad de base que hace germinar la competencia literaria.

- La valoración requiere necesariamente comprender y ésta es la actividad más compleja que realiza la competencia literaria.

En primer lugar, Propp (1985) asegura que los cuentos contribuyen a la progresiva acumulación de conocimientos dada su propia estructura interna, una estructura donde tanto el argumento como las motivaciones constituyen en realidad los elementos del cuento, quedando su distribución y agrupamiento determinados por la estructura constante de composición y específica del cuento. Tal es la progresiva acumulación de conocimientos, que Propp propone incluso formas concretas para hacer entrar a los personajes en escena durante el transcurso de los acontecimientos narrativos.

Por otra parte, si la formación de la competencia literaria está relacionada con la lectura, ¿acaso los cuentos no fomentan los hábitos lectores? Aparicio Martínez (2004) asegura que los cuentos, al suponer un contacto lúdico y placentero con el mundo de la literatura, favorecerán indefectiblemente la posterior adquisición de hábitos lectores así como la asunción de pequeñas normas y la distinción entre lo que está bien y lo que está mal.

Por último, señalamos el valor de los cuentos para facilitar la comprensión debido al modo en que captan la atención de los niños, posibilitando así un mejor seguimiento de los sucesos narrados.

Concluimos afirmando que con nuestra investigación se contribuye a, como afirma Cañamares Torrijos (2008), la necesaria búsqueda de alternativas 
lúdicas con las que animar a leer, pues la diversión y la participación son esenciales en los primeros aproximamientos lectores.

\section{METODOLOGÍA}

\subsection{OBJETIVOS DEL ESTUDIO}

- Diseñar una actividad en torno al cuento que permita repentizar una historia, valorar el lenguaje oral como vehículo de transmisión, conocer la estructura inicio, nudo y desenlace, comprender el concepto de adjetivos calificativos y antónimos y adaptar teatralmente un cuento, todo ello teniendo en cuenta las características del alumnado destinatario.

- Analizar las diferencias significativas entre los resultados obtenidos por el alumnado participante en la actividad antes de su implementación (pretest) y los hallados una vez finalizada (postest).

- Evaluar la utilidad y el grado de satisfacción de la actividad diseñada para el desarrollo de la competencia en comunicación lingüística, tanto desde la perspectiva del alumnado participante como desde la de los distintos profesionales de la docencia presentes durante su desarrollo.

\subsection{Muestra}

Nuestra investigación se ha llevado a cabo en un colegio de financiación pública y producción privada de la Región de Murcia, el cual oferta enseñanza en los niveles educativos de Educación Infantil, Educación Primaria y Educación Secundaria Obligatoria, teniendo en cada uno de ellos dos líneas por curso.

Los participantes que tomaron parte en nuestra actividad los dividimos en dos grupos: por una parte 47 alumnos que cursan sus estudios en $3 .^{\circ}$ de Educación Primaria (21 niñas y 27 niños) y por otro, sus maestras-tutoras.

\subsection{DiSEÑO DE LA INTERVENGIÓN}


En nuestra investigación se aúnan aspectos cuantitativos y cualitativos, de acuerdo con los objetivos concretos a los que pretendemos dar respuesta. Nos ubicamos, pues, ante un estudio pre-experimental en el que se realizan dos mediciones (una previa a la intervención y otra posterior) y con un diseño descriptivo-comparativo.

Por medio de esta indagación se pretende obtener información precisa en lo que concierne a la competencia en comunicación lingüística del alumnado de tercer curso Educación Primaria que tomó parte en esta investigación, antes y después de la puesta en práctica de nuestra actividad diseñada en torno al cuento.

Cabe precisar que en nuestro enfoque también se ha considerado el análisis previo de la evaluación de la competencia en comunicación lingüística del alumnado participante a través de la percepción de sus maestras-tutoras pues, valgan las palabras de Rodríguez Polo (1999), partir del nivel de desarrollo del alumnado es algo necesario para cualquier intervención educativa. Nos mostramos a favor de lo señalado, pues identificar y valorar el grado de consecución de la competencia en comunicación lingüística inicial nos permite adaptar nuestra intervención al nivel del que partimos.

Finalmente, oportuno es mencionar que la finalidad de nuestra intervención no es solo explotar las posibilidades didácticas de los cuentos y relatos, sino que, además, pretendemos que a través de ellas se produzca una mejora en el nivel de competencia en comunicación lingüística. Por ello, al finalizar realizaremos la evaluación de los indicadores a través de unos cuestionarios finales destinados a alumnos y docentes, pues estaremos analizando los logros alcanzados por los alumnos en la competencia en comunicación lingüística (eficacia) o el grado de satisfacción de los niños (pertinencia).

Hemos pretendido que el diseño de los cuentos corra a cargo de los alumnos pues tal y como dice López Díaz (2009, 5): "los cuentos inventados y personalizados, además de ser potentes herramientas de educación y enseñanza, permiten establecer un nexo fortísimo con los niños". Al personalizarlos, los niños se sienten verdaderamente especiales. Por otra parte, el cuento no solo se torna de este modo en una actividad de aprendizaje, sino también en un recurso didáctico en su más amplia extensión.

Señalamos que, para diseñar nuestra intervención, se han considerado una serie de principios de intervención educativa, lo que nos lleva a enmarcar 
nuestro proceso de enseñanza-aprendizaje dentro de una concepción constructivista. De esta manera en los procesos de aprendizaje intervinieron los propios alumnos, los contenidos a tratar y, por supuesto, los agentes mediadores de los mismos: compañeros y maestros, centrando así la experiencia para el fomento de la competencia en comunicación lingüística en "dimensiones de tipo cualitativo, comunicativo y en los supuestos del constructivismo y del aprendizaje significativo" (López Valero y Jerez Martínez, 2010, 7).

\subsection{INSTRUMENTOS DE RECOGIDA DE INFORMACIÓN}

- Protocolo de observación sistemática para maestros. Se trata de un cuestionario semiestructurado que fue facilitado a los maestros-tutores al finalizar la experiencia. Con la información aportada pretendemos conocer su valoración de la misma, destacando los puntos débiles y fuertes. Esto nos permitirá enriquecer las propuestas de mejora de nuestra experiencia innovadora. Queda estructurado en tres partes: introducción, cuerpo de preguntas y puntos fuertes y débiles y comentarios.

Con la introducción se indica al docente que nos transmita su opinión y valoración sobre la actividad y con el cuerpo de preguntas (conformado por cinco preguntas cerradas simples dicotómicas con dos opciones de respuesta -Sí y No-) se interroga sobre el grado de motivación del alumnado durante el desarrollo de la experiencia, su grado de aceptación, la adquisición de vocabulario novedoso, si estima que el alumnado ha desarrollado su competencia en comunicación lingüística y, finalmente, si piensa que se han trabajado contenidos de la asignatura Lengua castellana y Literatura para el curso. Finalmente, en los puntos fuertes y débiles y comentarios se recogen tres cuestiones de respuesta abierta con las que pedimos a los docentes que señalen los puntos fuertes y débiles de la actividad, así como cuantas consideraciones estimen oportunas.

- Prueba de conocimientos previos para el alumnado, estructurada en dos partes diferenciadas. La primera queda conformada por seis cuestiones objetivas de complementamiento de respuesta breve con las que se pregunta qué es y qué hace un cuentacuentos, cómo estiman que se han transmitido muchos de los cuentos tradicionales que hoy día conocemos y qué es un verbo, un adjetivo y un sustantivo. La segunda parte consta de nueve preguntas cerradas de alternativa múltiple (Poco, Regular, Bastante y Mucho) con las que se pretende conocer la opinión de los niños en 
relación a las posibilidades colectivo-creativas de los cuentos, la posible vinculación cuento-imagen, requisitos de escritura, posibilidades de creación a partir de la modificación previa de verbos, adjetivos y sustantivos y susceptibilidad de adaptación teatral de un cuento.

- Prueba de rendimiento de los alumnos, conformada por cuatro partes. Las dos primeras son idénticas a la prueba de conocimientos previos, la tercer parte consta de nueve preguntas cerradas de alternativa múltiple (Poco, Regular, Bastante y Mucho) con las que se recoge información sobre su grado de satisfacción con la actividad realizada, su utilidad para el desarrollo y mejora de aspectos vinculados a la competencia en comunicación lingüística, para con el aumento de su interés y comprensión hacia los cuentos y para trabajar las competencias sociales y cívicas. La cuarta parte consta de dos preguntas de respuesta abierta o libre con las que han de indicar lo aprendido $\mathrm{y}$, libremente, proporcionar cuantos comentarios estimen oportunos.

\subsection{Plan de tratamientos y análisis de datos}

Una vez recogida la información, procedimos a la identificación de cada uno de ellos con un código número y, posteriormente, a la operativización de las variables y a la elaboración de las matrices de datos correspondientes con el paquete estadístico SPSS 15.0 para Windows (Statistical Package for the Social Sciences for Windows, vers. 15.0.1., 2006).

Elaboradas las matrices de datos, procedimos a los análisis pertinentes para dar respuesta a los objetivos planteados. Sin embargo, en primer lugar, antes de realizar el análisis confirmatorio de los datos, hicimos un análisis exploratorio con la finalidad de detectar posibles datos anómalos y poder solventarlos. El análisis confirmatorio de los datos se ha realizado a un nivel descriptivo (análisis univariables y análisis bivariables).

Por otra parte, para el análisis cualitativo con el software ATLAS.ti de las producciones realizadas por los niños hemos empleado el siguiente sistema de categorías:

1. Variabilidad de vocabulario: número de verbos de los cuentos originales modificados correctamente.

2. Variabilidad de vocabulario: número de verbos de los cuentos originales no modificados. 
3. Variabilidad de vocabulario: número de sustantivos de los cuentos originales modificados correctamente.

4. Variabilidad de vocabulario: número de sustantivos de los cuentos originales no modificados.

5. Variabilidad de vocabulario: número de adjetivos de los cuentos originales modificados correctamente.

6. Variabilidad de vocabulario: número de adjetivos de los cuentos originales no modificados

\section{RESULTADOS}

Resultados alcanzados en el objetivo Diseñar una actividad en torno al cuento que permita repentizar una historia, valorar el lenguaje oral como vehículo de transmisión, conocer la estructura inicio, nudo y desenlace, comprender el concepto de adjetivos calificativos y antónimos y adaptar teatralmente un cuento, todo ello teniendo en cuenta las características del alumnado destinatario.

La evaluación de su nivel de competencia en comunicación lingüística inicial está referido a la totalidad del grupo clase (lo cual incluye a dos alumnos que no asistieron en el momento de la puesta en práctica de nuestra actividad). De todos ellos, un $43.8 \%$ son niñas y un $56.3 \%$, niños.

Los niños, según las valoraciones emitidas por sus maestras-tutoras, poseen un mejor nivel de vocabulario, de nivel de expresión oral y escrita, de comprensión y expresión oral, de respeto por las diversas opiniones de sus compañeros y de implicación al trabajar en grupo. Por el contrario, apreciamos que las niñas obtienen valoraciones más positivas en lo referido a su nivel de fluidez verbal. La prueba de rangos $U$ de Mann-Whitney señala que las diferencias apreciadas a nivel meramente descriptivo no han de ser consideradas estadísticamente significativas, no existiendo, por consiguiente, un efecto estadísticamente significativo del sexo en ninguno de los niveles anteriormente señalados: Nivel de vocabulario $(U=281.000$ y $p>.05)$, nivel de comprensión lectora/escrita $(U=271.500$ y $p>.05)$, nivel de expresión oral y escrita $(U=268.000$ y $p>.05)$, nivel de comprensión y expresión oral ( $U=$ 245.500 y $p>.05)$, nivel de fluidez verbal $(U=255.500$ y $p>.05)$, nivel de respeto por las diversas opiniones de los compañeros $(U=268.500$ y $p>.05)$, 
nivel de implicación al trabajar en grupo $(U=266.500$ y $p>.05)$ y nivel de creatividad ( $U=262.500$ y $p>.05)$.

Así mismo, comprobamos que la mayoría del alumnado posee un nivel alto en la práctica totalidad de los aspectos planteados para evaluar la competencia en comunicación lingüística, a excepción del nivel de fluidez verbal, en el que existe un predominio de aquellos alumnos cuyo nivel es medio.

Considerando lo anterior, planteamos la actividad Los cuentacuentos, la cual se articula en tres sesiones. En nuestra primera sesión cumplimentando la prueba de conocimientos o formación previos diseñada, a fin de medir el nivel de competencia en comunicación lingüística inicial.

Seguidamente se invitó a los niños a formar un círculo y explicamos que uno de ellos iba a desempeñar el papel de cuentacuentos, lo cual dio lugar a que se abordaran las siguientes preguntas: ¿Saben lo que es eso? (contenidos de lengua); ¿saben cómo han perdurado los cuentos que actualmente conocen? (contenidos de lengua); ¿cómo creen que se han transmitido algunos de los cuentos que hoy día conocemos? (más contenidos de lengua).

A continuación, preguntamos a la clase si conocían (por ejemplo) el cuento de Los tres cerditos. Como es de esperar, la gran mayoría de los alumnos respondió afirmativamente al unísono, tras lo cual seleccionamos a un voluntario que se prestó a contar a sus compañeros el cuento referido.

Una vez finalizada la historia, y a fin de conocer qué les pareció a los alumnos el cuento que su compañero acababa de narrar, pedimos al grupo clase que nos indicase si estimaban que la versión seguida por el compañero era fiel a la original, si había realizado algunas modificaciones o si se había respetado la estructura inicio, nudo y desenlace. Del mismo modo, pedimos que reflexionaran sobre la necesidad de incorporar en los cuentos vocabulario amplio y rico (verbos, adjetivos), así como la utilización de figuras literarias básicas, como comparación, personificación y metáfora.

Con lo planteado, formamos y desarrollamos el intertexto lector de los niños, lo cual, según Mendoza Fillola $(2008,108)$ es necesario para que sus lecturas constituyan el fondo de conocimientos y experiencias literarias.

Seguidamente, hicimos saber a los alumnos que iban a tener la oportunidad de convertirse en cuentacuentos y que, entre todos, iban a crear un cuento que repentizarían sin previamente haber pensado nada. Para ello, se le enseñó al 
grupo clase un conjunto de láminas donde, para su elaboración, se prestó atención en que apareciera una amplia variedad de lugares, personajes y animales desempeñando acciones distintas, así como un grado de apertura que permitiera a los niños una interpretación subjetiva, tales como un barco, un búho, un pato, un castillo, un ordenador, un avión y unos niños.

Los animales se constituyen como un elemento fundamental en las imágenes debido a que la familiaridad y confusión con el mundo animal es una de las constantes del cuento maravilloso y en general de la literatura infantil (López Tamés, 1989). No obstante, también incorporamos láminas que ilustran a protagonistas humanos, aproximándonos así al tránsito que los niños experimentan a partir de los ocho años hacia los denominados cuentos de la vida real.

Fernández Quirós (2010) se muestra a favor del uso de imágenes pues reconoce que ayudan a la comprensión de la historia y a su vez ofrecen contenido académico que tradicionalmente se había adjudicado a asignaturas o áreas específicas.

Cabe destacar que todas las imágenes de las láminas empleadas poseen licencia Creative Commons de distribución no comercial.

Se indicó a los niños que las imágenes constituían nuestro medio de creación cuentística y que cada uno tendría la oportunidad de regalar a sus compañeros un fragmento del cuento que guardase relación con la descripción pictórica de las láminas, el cual debía ser respetado por el compañero siguiente, quien tendría que continuar la historia respetando el hilo argumental proporcionado por sus compañeros.

Las láminas creadas suponen un buen método de creación y evocación literaria pues Pérez Valverde $(2008,539)$ recoge las declaraciones del autor de las historias de Narnia, C.S. Lewis, en relación a su proceso creativo, declarando éste:

Haber ideado sus relatos a partir de la concentración en unas imágenes que solían venirle a la cabeza desde su adolescencia: "todo empezó con la imagen de un fauno portando un paraguas y paquetes en un bosque nevado" (Lewis, 1966, 79). Esta declaración corrobora el poder evocador de las imágenes al que se ha hecho referencia. 
Además, según Campbell (1949), "los motivos que hallamos en los cuentos tradicionales y los mitos, análogos a los que aparecen en los sueños, componen un lenguaje de imágenes que encierra verdades de orden metafísico, psicológico y sociológico" (citado en Pérez Valverde, 2008, 539).

Por supuesto, al admirar un cuadro se conectan dos mundos: el del observador y el del pintor, y es que:

El lector aporta sus conocimientos previos y recibe, como en el acto de leer, un texto expreso en forma de pintura. En palabras de Bigas y Correig (2008): "El lector construye activamente el significado del texto según sus conocimientos y experiencias previas y el objetivo que guía su lectura." (Fernández Quirós, $2010,62)$.

Pedimos un voluntario para que barajase las láminas, pues se trata de jugar con el orden en que estas se sucedan. La aparición de una lámina antes de otra dará lugar a la creación de un argumento necesariamente diferente del que podría derivarse de haber seguido un orden distinto. Por tanto, este material posee un gran valor didáctico pues permite su reutilización sin riesgo de caer en la repetición y monotonía. Sus posibilidades creativas son prácticamente indeterminadas.

Barajadas las láminas, las situamos en el centro del círculo, cara abajo, con lo que se pretendió aumentar el factor sorpresa e incitar la atención por parte de los niños. Seguidamente, y de forma individual a medida que lo fuimos indicando, los niños se levantaron para coger una lámina. Cada uno de los niños enseñó su imagen al resto de los compañeros y, a continuación, se inventó un fragmento del cuento que guardara relación con esa imagen. Finalizada su intervención, expuso su lámina en un panel para ello habilitado, a fin de que toda la clase pudiera recordar la secuencia seguida del cuento.

Se pretendió que cada uno de los alumnos repentizase un fragmento de la historia atendiendo a la imagen que le había tocado a fin de crear entre toda la clase un cuento compartido de creación conjunta. Se puso atención en explicar a los alumnos que la historia debía guardar coherencia, de modo que si el primer alumno decía que "Esta de aquí es una niña que una mañana se fue a jugar al parque con su mejor amiga, Cinthia", el segundo alumno, aun teniendo plena libertad para interpretar su lámina, debía ajustarse a la información dada por su compañero.

Durante la realización de la experiencia, se proyectó en la pantalla del aula un documento de texto en blanco, de modo que, a medida que cada alumno fue 
repentizando su fragmento del cuento, fuimos transcribiendo sus aportaciones, procurando respetar siempre la idea dada por los alumnos e intentando enriquecer el vocabulario y utilizar una sintaxis adecuada.

La segunda sesión se inició con la formación de grupos de tres componentes de diferente nivel competencial comunicativo-lingüístico. Esto corrió a cargo del maestro-tutor de la clase, quien, según nuestras indicaciones, agrupó al alumnado considerando su nivel de vocabulario, comprensión lectora y escrita, expresión escrita, comprensión oral, expresión oral, fluidez verbal, hábitos grupales, hábitos lectores y creatividad.

Una vez constituidos los grupos, repartimos y leímos en voz alta el cuento que transcribimos la sesión anterior. Así mismo, dimos a cada grupo una copia del cuento. A continuación, explicamos a la clase que cada grupo debía seleccionar una de estas opciones:

- Subrayar los adjetivos calificativos que encontraran en la historia y modificarlos por sus antónimos.

- Subrayar los verbos que encontraran en la historia y cambiarlos por otros de significado opuesto u otros distintos.

- Subrayar los sustantivos que encontraran en la historia y modificarlos por otros diferentes.

Finalmente, los alumnos reescribieron el cuento de forma que guardase coherencia con la modificación de palabras efectuada. Indefectiblemente, debieron modificarse muchos aspectos de la trama argumental de los cuentos originales.

Nuestra tercera sesión se inicia con la puesta en común de los cuentos modificados por cada uno de los grupos establecidos. Durante las exposiciones, el resto de la clase se sentó frente a sus compañeros, sin localizarse a una distancia excesivamente alejada. Tal y como comenta Bryant (1985), los pequeños necesitan una proximidad física para sentirse mentalmente próximos. Además, sabemos de la buena predisposición de los alumnos a escuchar un cuento ya que, valgan las palabras de Jean (1988), los educadores y los maestros de escuela saben claramente que a los niños les gusta que se les cuente un libro. Finalizadas las exposiciones se procedió a la votación por parte de los niños del cuento que más les había gustado. 
Invertimos el resto de la sesión en su representación teatral por toda la clase, siguiendo las indicaciones que para ello ofrecimos.

El motivo por el que decidimos concluir la experiencia con una adaptación teatral es que quizá sea en el teatro en donde la autonomía infantil alcanza mayor reconocimiento (López Tamés, 1989). Del mismo modo, Cervera (1992) no duda en admitir que los cuentos, la poesía y el teatro son los géneros básicos de la literatura infantil.

Finalizamos la experiencia repartiendo la prueba de rendimiento diseñada, a fin de determinar la mejora tras la implementación de la experiencia producida en el nivel de competencia en comunicación lingüística de los alumnos. Del mismo modo, aprovechamos para interrogarlos sobre su percepción en referencia a si la experiencia les sirvió para aumentar su vocabulario y si fue de su interés, entre otros aspectos.

Resultados alcanzados en el objetivo Analizar las diferencias significativas entre los resultados obtenidos por el alumnado participante en la actividad antes de su implementación (pretest) y los hallados una vez finalizada (postest).

Los análisis de las producciones ponen de manifiesto, tal y como se recoge en la Tabla 1, que los niños han participado correctamente. En efecto, comprobamos que los porcentajes de los adjetivos, sustantivos y de los verbos presentes en los cuentos inicialmente creados (El Señor Búho con el grupoclase de $3 .^{\circ}$ A y Las aventuras de Ángel con el de $3 .^{\circ}$ B) que han sido modificados correctamente durante la creación de los cuentos de nuestra actividad son superiores a los que corresponden a los no modificados (a excepción del cuento Zombies en la isla, donde encontramos una mayor presencia de verbos no modificados y Ángel y el malvado perro, donde los porcentajes de sustantivos modificados y no modificados se distribuyen equitativamente).

Centrándonos en el análisis comparativo pretest-postest, los resultados hallados con el estudio de las respuestas dadas al inicio de la actividad y tras su finalización nos conducen a evidenciar una serie de mejoras en la competencia en comunicación lingüística:

- De los 11 alumnos que respondieron incorrectamente a la pregunta "¿Qué es un cuentacuentos?" con anterioridad a la puesta en práctica de 
nuestra actividad, todos $(100 \%)$ han respondido correctamente a tal cuestión una vez hubo finalizado nuestra actividad (véase Tabla 196).

Así mismo, si bien antes de la puesta en práctica de la actividad, 34 niños respondían correctamente a tal cuestión (75.6\%), tras implementarse, el porcentaje aumenta al $100 \%$. Estos resultados muestran una mejora en la condición antes-después, siendo la diferencia siendo la diferencia estadísticamente significativa (McNemar $p<.01)$.

- Con anterioridad al desarrollo de la actividad, el 73.3\% del alumnado indicó correctamente qué hace un cuentacuentos, mientras que tras su desarrollo, el porcentaje se ve incrementado hasta un $97.8 \%$. Nos situamos ante una mejora estadísticamente significativa en la condición del momento inicial al posterior de la puesta en práctica de nuestra actividad $($ McNemar $p<.01)$.

- De los 38 niños que inicialmente no supieron identificar cómo se han transmitido los cuentos que actualmente conocemos, 31 de ellos (81.6\%) sí proporcionan respuestas correctas tras participar en nuestra actividad. Del mismo modo, se aprecia que mientras que en el pretest únicamente un $15.6 \%$ fue capaz de proporcionar una respuesta adecuada en relación a tal aspecto, en el postest este porcentaje se ve incrementado a un $82.2 \%$. Esta mejora es estadísticamente significativa $($ McNemar $p<.001)$.

- En el pretest, el $71.1 \%$ del alumnado indicó correctamente qué es un verbo, mientras que en el postest este porcentaje aumenta al 97.8\%. Nos ubicamos ante una mejora en la condición del antes al después de la puesta en práctica de nuestra actividad, siendo la diferencia estadísticamente significativa $($ McNemar $p<.01)$.

- Según comprobamos, un $75.6 \%$ de los niños indicó de forma correcta y previamente a la puesta en práctica de nuestra actividad qué es un sustantivo, mientras que, tras participar en ésta, el porcentaje de alumnos que así lo hace se incrementa hasta el $86.7 \%$. Se deduce, pues, cierta mejora en la condición antes-después, aunque no podemos afirmar que ésta no sea resultado del azar (McNemar $p>.05)$.

- Se aprecia una mejora porcentual estadísticamente significativa en las respuestas dadas por el alumnado a la pregunta "¿Qué es un adjetivo?": del $48.9 \%$ (pretest) al $75.6 \%$ (postest); (McNemar $p<.01)$. 
- En el pretest, el $88.8 \%$ indicó como "bastante" y "muy" posible crear un cuento con la ayuda de sus compañeros; en el postest, así lo hace un $100 \%$. Afirmamos que esta mejora porcentual es estadísticamente significativa $(Z=-2.993$ y Wilcoxon $p<.01)$.

- Previamente al desarrollo de nuestra actividad, el 77.8\% del alumnado señala como posible crear un cuento a partir de imágenes; una vez concluye ésta, el porcentaje aumenta a un $97.8 \%$. Existen mejoras que son estadísticamente significativa $(Z=-4.349$ y Wilcoxon $p<.001)$.

- Al preguntar a los niños antes de la actividad si una imagen podía tener varias interpretaciones, solo el $46.6 \%$ se mostró a favor y consideró que, efectivamente, podía ser interpretada de modos diversos; tras finalizar la experiencia, el porcentaje de alumnos que estima esto como factible aumenta a un $51.2 \%$. Si bien se aprecia cierta mejora (véase Tabla $204)$, ésta no puede ser considerada estadísticamente significativa $(Z=$ 1.212 y Wilcoxon $p>.05)$.

- En el pretest, el $88.9 \%$ señaló la necesidad de poseer un vocabulario amplio a la hora de escribir un cuento; en el postest, lo señala un $100 \%$. La implementación de nuestra actividad ha dado lugar a una mejora que es estadísticamente significativa $(Z=-2.430$ y Wilcoxon $p<.05)$.

- Si bien se aprecia que en el pretest, el $91.2 \%$ del alumnado reconoció como "bastante" y "muy" necesario la correcta redacción de un cuento y en el postest este porcentaje aumenta al $95.6 \%$, no podemos afirmar que la opinión de los niños al inicio $(M d=4)$ y al finalizar la experiencia $(M d=4)$ haya cambiado de modo estadísticamente significativo $(Z=-790$ y Wilcoxon $p>.05)$.

- Antes de la puesta en práctica de nuestra actividad, el 37.8\% de los niños se mostró a favor de la posibilidad de crear un cuento nuevo a partir de la modificación de sustantivos de otro cuento ya existente, mientras que tras participar en ésta, el porcentaje ha aumentado al 95.6\%. Se aprecian diferencias en las opiniones expresadas por los niños en los momentos antes $(M d=3)$ y después $(M d=4)$ de la puesta en práctica de nuestra actividad, siendo éstas estadísticamente significativas $(Z=-.790$ y Wilcoxon $p<.001)$. 
- En el pretest, el $35.5 \%(M d=3)$ y el $35.6 \%(M d=3)$ del alumnado consideró que era posible crear un cuento nuevo a partir de la modificación de los verbos y adjetivos de otro cuento, respectivamente, mientras que en el postest, el porcentaje que así lo estima es del $93.3 \%(M d=4)$ y del $100 \%$ $(M d=4)$. Tanto en el caso de las respuestas dadas para la creación de un cuento a partir de la modificación de los verbos $(Z=-4.359$ y Wilcoxon $p<$ $.001)$ como de los adjetivos $(Z=-5.272$ y Wilcoxon $p<.001)$ de otro cuento, las diferencias son estadísticamente significativas.

- En el pretest, ocho de cada 10 alumnos consideraron como "muy" y "bastante" posible adaptar teatralmente un cuento; en el pretest el porcentaje aumenta a un $97.8 \%$. Se aprecia un cambio en las respuestas ofrecidas por los niños con anterioridad al inicio de nuestra actividad $(M d=3)$ y tras su finalización $(M d=4)$, siendo esta diferencia estadísticamente significativa $(Z=-3.842$ y Wilcoxon $p<.001)$.

Resultados alcanzados en el objetivo Evaluar la utilidad y el grado de satisfacción de la actividad diseñada para el desarrollo de la competencia en comunicación lingüística, tanto desde la perspectiva del alumnado participante como desde la de los distintos profesionales de la docencia presentes durante su desarrollo.

Las respuestas dadas a la pregunta " $¿$ Te ha gustado esta actividad?" señalan que a un $88.9 \%$ le ha gustado "mucho" y a un $6.7 \%$ "bastante", no existiendo ningún niño que haya señalado la opción de respuesta "nada".

Podemos afirmar que esta actividad ha tenido un buen grado de acogida por parte de los niños, pues comprobamos que el $100 \%$ está dispuesto a repetirla (un $82.2 \%$ indica que le gustaría "mucho" volver a realizarla en un futuro y un $17.8 \%$ contesta con un "bastante").

De igual modo, las respuestas dadas a la pregunta ¿Crees que te ha ayudado a escribir mejor?" señalan que la mayoría de los niños reconoce y admite la utilidad de la actividad por nosotros confeccionada para este fin: un $62.2 \%$ responde con "mucho" y un $24.4 \%$ con "bastante". Además, la mayoría vuelve a imponerse $(97.8 \%)$ al asegurar que esta actividad los ha ayudado "mucho" y "bastante" a mejorar en la asignatura de Lengua castellana y Literatura.

El resto de porcentajes relativos a las respuestas del alumnado insiste en reconocer la positiva contribución de nuestra actividad para con aspectos 
tales como la mejor predisposición a la hora de escribir un cuento (el 75.6\% considera que ahora están en "muchas" mejores condiciones de hacerlo que antes y un $17.8 \%$ en "bastantes" mejores condiciones) y la atracción hacia los cuentos experimentada por los niños (un $71.1 \%$ confiesa sentirse "muy" atraído hacia ellos y un $22.2 \%$ "bastante" atraído).

Igualmente positivos son los resultados hallados en la pregunta $"$ Consideras que esta actividad te ha permitido apreciar y valorar el trabajo de tus compañeros?", pues nueve de cada 10 niños contestan con "bastante" y "mucho". Más contundentes son los porcentajes que nos informan que con esta actividad los niños han aprendido "mucho" y "bastante" a respetar la opinión de los demás (93.4\%) y aquéllos que estiman que trabajar en grupo les ha resultado "muy" y "bastante" enriquecedor (93.3\%).

A fin de disipar cualquier duda sobre la utilidad de esta actividad, los alumnos han aportado abiertamente lo que han aprendido con ella, encontrando un claro predominio de las razones "muchas cosas" (28.9\%) y "quién es un cuentacuentos" $(17.8 \%)$.

En cuanto a los comentarios aportados por el alumnado, destacamos "me ha gustado mucho y quiero repetirlo" (35.6\%) y "quiero repetirlo" $(22.2 \%)$.

En lo que respecta a la valoración de las docentes presentes durante su realización, encontramos que las dos maestras-tutoras de las líneas A y B que conforman el tercer curso de Educación Primaria que participó en el desarrollo de la presente actividad se manifiestan a favor de la buena motivación mostrada por sus alumnos, así como su buen grado de aceptación, la adecuada adquisición de vocabulario novedoso, el buen desarrollo de la competencia en comunicación lingüística alcanzado y la impartición de contenidos de Lengua castellana y Literatura.

Como punto fuerte, uno de las maestras señala "El hecho de que tengan que inventar una parte del cuento a partir de una imagen" y, el otro, "La realización de cuentos a través de imágenes y en grupos y el trabajo de sustantivos, verbos y adjetivos" (50\% cada respuesta). En cuanto a los puntos débiles, una de ellas (50\%) señala "El comportamiento de los alumnos porque son inquietos".

Para concluir, las consideraciones señaladas abiertamente por las maestras son las siguientes: "Que se haga alguna vez más a lo largo del curso" (50\%) y "Estaba todo muy bien" (50\%). 


\section{CONCLUSIONES Y PROPUESTAS DE MEJORA}

Tras el diseño de nuestra actividad podemos concluir que en ella los cuentos poseen un marcado protagonismo, persiguiéndose con esto, entre otros aspectos, captar el interés de los niños y estimular el placer por los libros (Sandoval, 2005).

Afirmamos también que el diseño se ha realizado atendiendo a las características de los alumnos, aspecto que hemos perseguido a través del estudio y evaluación de la competencia en comunicación lingüística de los alumnos participantes, tratando así de adecuar la dificultad de las actividades al nivel competencial de los niños. Podemos, por tanto, afirmar que partimos del nivel de desarrollo del alumnado.

Además, se aprecia la relevancia ofrecida al aprender a aprender, a la creatividad y al aprendizaje significativo, estando este último, como señalan Guerrero Ruiz y López Valero (1993), mantenido en un modelo de trabajo nocional-funcional, de enfoque comunicativo, y en un estilo experimental.

Si bien la creatividad es consustancial al ser humano, señalan Franco y Alonso (2011) que la escuela normalmente la relega a una actividad secundaria, dándole mayor importancia a la adquisición de contenidos y conceptos que tienden a olvidarse debido a su falta de significatividad para el alumno en otros contextos o situaciones, por lo que nuestra actividad pretende abordar esta realidad incorporando técnicas que la desarrollan en un contexto, buscando el desarrollo del pensamiento creativo.

Concluimos que nuestra actividad, a través de las mejoras estadísticamente significativas acaecidas entre los resultados inicialmente obtenidos por los niños antes de su participación y los hallados tras su conclusión, y a través de la correcta participación de los niños, quienes han puesto en práctica los contenidos impartidos (tal y como se deduce a partir de las producciones analizadas), contribuye a:

- Aumentar la competencia literaria del alumnado, aspecto esencial según afirma Carrillo García (2008) al señalar que "podemos decir que la presencia de la Literatura Infantil y Juvenil es escasa y que la consideración de la Competencia Literaria como objetivo es prácticamente nulo" $(2008,20)$. 
- Ayudar a la adquisición de nuevo vocabulario, el desarrollo de la competencia literaria del alumnado y a producir un intercambio comunicativo, aspectos todos ellos motivadores y que estimulan y desarrollan la imaginación (Carrillo García, 2008).

- Fortalecer los hábitos lectores de los niños, debido a que nuestras actividades les han permitido vivir y crear los distintos cuentos trabajados.

- Convertir a los niños en lectores que viven en los libros, gozan, ríen, salen de sí mismos y conocen mundos diferentes (Tejerina, Rodríguez, Bringas de la Peña, Echeverría, Gutiérrez, Bolton, Amparán y Gutiérrez 2006).

- Los objetivos principales que nos debemos marcar con la utilización de la narración en las aulas: adquisición de vocabulario, desarrollo de la competencia literaria, motivación, estímulo y desarrollo de la imaginación y, sobre todo, intercambio comunicativo (López Valero y Encabo Fernández, 2001).

- Abrir las posibilidades de elección creativa al gusto de los alumnos, haciendo justicia a las palabras "el alumno es el protagonista activo en el proceso de comunicación lingüística en su doble dimensión: de recepción y de creación" (Caro Valverde, 2006, 83).

- La comprensión de los niños de algunas de las características presentes en el estilo literario de la literatura infantil y en los cuentos propuestos por Lluch y Janeth (2007), tales como el planteamiento de una narración con múltiples interpretaciones que permita y reclame relecturas, propuesta discursiva rica, con personajes llenos de matices y lejos de los estereotipos, figuras retóricas como metáforas o alegorías, profusión y gran variedad de adjetivos, descripción de lo que sienten los personajes, descripción de lo que producen los paisajes, presencia mayoritaria del narrador, variedad de oraciones y cambio en el orden de los elementos para conseguir diferentes efectos estilísticos.

Afirmamos que nuestra actividad ha gozado de una buena acogida por parte del alumnado, pues a la mayoría le han gustado las actividades y se muestra a favor de volver a repetirlas. 
Los niños también han aprendido a respetar la opinión de los demás y a apreciar y valorar el trabajo de los compañeros de clase. Quedan evidenciadas, pues, las aportaciones de Bortolussi (1985), al demostrarse que la actividad, erigida en torno al cuento, permite una interacción, una cooperación, una coexistencia, una organización, una creación colectiva.

Así mismo, la mayoría del alumnado vuelve a reiterar su deseo de volver a repetir una actividad similar en un futuro, aspecto que hemos perseguido otorgando a la actividad un fuerte componente lúdico.

A partir de nuestra propia experiencia pudimos apreciar dicho grado de satisfacción, aspecto señalado no solo por los alumnos, sino también por las propias docentes de todos los cursos, las cuales coinciden en la adecuada motivación y grado de aceptación existentes durante la realización de las distintas experiencias.

Tampoco existe duda sobre si la actividad ha sido útil para el desarrollo de la competencia en comunicación lingüística, aspecto que, si bien se deduce de las diferencias significativas acaecidas entre los resultados obtenidos por el alumnado de Educación Primaria en el pretest en contraposición con las mejoras del postest para la práctica totalidad de los aspectos abordados, los propios alumnos reiteran afirmando que participar en sus distintas actividades les ha sido útil para mejorar en la asignatura de Lengua castellana y Literatura, lo que viene a reivindicar lo anteriormente señalado.

En cuanto a las propuestas de mejora para futuras investigaciones que sigan nuestra línea u otras similares, pueden admitirse las siguientes variaciones: si bien es cierto que las láminas empleadas posibilitan la creación de una cantidad casi ilimitada de cuentos (entrando en ello en juego el distinto orden con que éstas se presenten), es posible incorporar nuevas láminas con paisajes y protagonistas distintos. También hemos comprobado con la implementación de nuestra actividad que todos los niños han vinculado la lámina del dragón con el personaje antagonista de sus cuentos, lo que nos lleva a plantear la posibilidad de delimitar desde su inicio algunos aspectos relativos a la personalidad y psicología de los personajes, haciendo saber a los niños (por ejemplo) que el dragón es en realidad un ser tímido y bondadoso, mientras que por el contrario, el (aparentemente) indefenso pato que aparece en nuestras láminas alberga un corazón oscuro y frío. Sin lugar a dudas, esto daría lugar a un cambio de roles en los personajes de los cuentos a crear y, por consiguiente, desencadenaría en cuentos diferentes. 
Por otra parte, pensamos que cualquier experiencia de innovación debería de prolongarse en el tiempo; lógicamente no tenemos garantía de que lo realizado vaya a perdurar en los aprendizajes de los alumnos; pues al fin y al cabo, la nuestra tan solo ha sido una experiencia puntual. Hubiéramos conseguido un mayor nivel de generalización de haber llegado a más etapas educativas (como Educación Infantil o Educación Secundaria Obligatoria) a fin de evidenciar, aún más, el potencial educativo, didáctico y pedagógico que ofrecen los cuentos.

\section{REFERENCIAS BIBLIOGRÁFICAS}

Aparicio Martínez, E. (2004). El cuento: su valor educativo. Aula y docentes. Recuperado de http://myslide.es/documents/el-cuento-y-su-valoreducativo.html

Bortolussi, M. (1985). Análisis teórico del cuento infantil. En M. Bortolussi (Ed.), La recepción infantil (pp. 82-128). Madrid: Alhambra.

Bryant, S. (1983). El arte de contar cuentos (décima edición). Barcelona: Hogar del Libro.

Cañamares Torrijos, C. (2008). Programaciones de animación a la lectura. Una propuesta para animar la lectura en Educación Infantil y Primaria. Glosas Didácticas, 17, 64-70. Recuperado de http://www.um.es/glosasdidacticas/numeros/GD17/06.pdf

Carrillo García, M. E. (2008). Roald Dahl y la literatura infantil y juvenil en la didáctica de las lenguas: una propuesta para la mejora de la competencia literaria en el aula. (Tesis de doctorado, Universidad de Murcia). Recuperado de http://digitum.um.es/xmlui/handle/10201/19892

Cerrilo, P. C. y Senís, J. (2005). Nuevos tiempos, ¿nuevos lectores? Revista OCNOS, 1, 19-33. Recuperado de https://ruiderae.revista.uclm.es/index.php/ocnos/article/download/166/1 47

Cervera, J. (1992). Teoría de la literatura infantil. Bilbao: Ediciones Mensajero.

Colomer, T. (2005). El desenlace de los cuentos como ejemplo de las funciones de la literatura infantil y juvenil. Revista de Educación, 1, 203-216. Recuperado de http://www.revistaeducacion.mec.es/re2005/re2005_16.pdf

Fernández Quirós, E. (2010). El arte y la literatura infantil y juvenil a través de un modelo de álbum ilustrado. Hekademos. Revista Educativa Digital, 7, 55-69. Recuperado de http://dialnet.unirioja.es/servlet/articulo?codigo $=3745675$ 
Franco, C. y Alonso, J. M. (2011). Diferencias entre cuentos conocidos y desconocidos en la estimulación de la creatividad infantil. Aula Abierta, 39(2), 113-122. Recuperado de

http://dialnet.unirioja.es/servlet/articulo?codigo $=3621387$

Guerrero Ruiz, P. (2008). Metodología de investigación en educación literaria. (El modelo ekfrástico). Murcia: Diego Marín.

Guerrero Ruiz, P. y López Valero, A. (1993). La didáctica de la lengua y la literatura y su enseñanza. Revista Interuniversitaria de Formación del Profesorado, 18, 21-27. Recuperado de http://www.aufop.com/aufop/uploaded_files/articulos/1273009341.pdf

Jean, G. (1988). El poder de los cuentos. Barcelona: Pirene.

Lluch, G. y Janeth, C. (2007) La evaluación de los libros para niños y jóvenes. Una investigación sobre la experiencia de FUNDALECTURA. Revista OCNOS, 3, 103-119. Recuperado de http://www.redalyc.org/articulo.oa?id=259120376007

López Díaz, C. (2009). El valor de los cuentos como parte de la educación en valores. Innovación y Experiencias Educativas, 14, 1-7. Recuperado de http://www.csicsif.es/andalucia/modules/mod_ense/revista/pdf/Numero_14/CONCEPCI ON_LOPEZ_1.pdf

López Tamés, R. (1989). Introducción a la literatura infantil. Murcia: Secretariado de Publicaciones.

López Valero, A. y Encabo Fernández, E. (2001). De mitos, leyendas y cuentos: necesidad didáctica del género narrativo. Contextos educativos, 4, 241-250. Recuperado de

http://dialnet.unirioja.es/servlet/articulo?codigo $=209698$

López Valero, A. y Jerez Martínez, I. (2010). Lectura, escritura y democracia de la cultura: experiencias con la creación literaria. Álabe. Revista de la Red de Universidades Lectoras, 2, 1-16. Recuperado de http://dialnet.unirioja.es/servlet/articulo?codigo $=3628316$

Mendoza Fillola, A. (2006). Las dos caras de la lectura: motivación y expectativas en el lector de Literatura Infantil. En Girona Latorre, L. (Ed.), La motivación a la lectura a través de la literatura infantil (pp. 926). Madrid: Instituto Superior de Formación del Profesorado.

Pérez Steve, P. (2009). La comprensión lectora y la competencia en comunicación lingüística en el nuevo marco curricular: algunas claves para su desarrollo. Educatio Siglo XXI, 27(1), 13-32. Recuperado de http://revistas.um.es/educatio/article/view/71081

Pérez Valverde, C. (2008). Discurso fantástico e inconsciente en la literatura infantil. En R. Sánchez García (Ed.), Lecciones azules. Lengua, literatura y didáctica (pp. 532-544). Madrid: Visor Libros. 
Propp, V. (1985). Morfología del cuento. Madrid: Akal bolsillo.

Rodríguez Muñoz, F. J. (2010). La competencia en comunicación lingüística a partir de la corrección de textos periodísticos: una experiencia docente. Espiral. Cuadernos del profesorado. Revista Digital del Centro del Profesorado Cuevas-Olula (Almería), 5(6), 53-64. Recuperado de http://www.cepcuevasolula.es/espiral.

Rodríguez Polo, J. (1999). Didáctica de la narración escrita: enseñanza del discurso narrativo en Educación Primaria. (Tesis de doctorado, Universidad de Granada). Recuperado de http://digibug.ugr.es/bitstream/10481/25989/1/Jose_A_Rodriguez_Polo. pdf

Rosal Nadales, M. (2010). Creación poética y competencia literaria: propuestas didácticas. Álabe. Revista de la Red de Universidades Lectoras. 2, 1-21. Recuperado de http://dialnet.unirioja.es/descarga/articulo/3628335.pdf

Salmerón Vílchez, P. (2004). Transmisión de valores a través de los cuentos clásicos infantiles. (Tesis de doctorado, Universidad de Granada). Recuperado de http://hera.ugr.es/tesisugr/15487441.pdf

Sandoval Paz, C. E. (2005). El cuento infantil: una experiencia de lenguaje integral. Revista ieREd: Revista Electrónica de la Red de Investigación Educativa, 1(2). Recuperado de http://revista.iered.org

Tejerina Lobo, I., Rodríguez Gutiérrez, B., Bringas de la Peña, F., Echevarría Arce, E., Gutiérrez Sebastían, R. Bolton Pearson, N., Amparán Cardín, F. y Gutiérrez Martínez-Conde, J. (2006). La caracterización del lector adolescente: una aproximación desde la objetividad y desde la subjetividad. Revista OCNOS, 2, 93-103. Recuperado de http://www.revista.uclm.es/index.php/ocnos/article/view/223 